\title{
Incorporating Polygenic Risk Scores in the ACE Twin Model to Estimate A-C Covariance
}

\author{
Conor V. Dolan ${ }^{1,4} \cdot$ Roel C. A. Huijskens ${ }^{1} \cdot$ Camelia C. Minică ${ }^{3,5} \cdot$ Michael C. Neale ${ }^{1,2} \cdot$ Dorret I. Boomsma $^{1}$
}

Received: 25 June 2020 / Accepted: 5 December 2020 / Published online: 1 February 2021

(c) The Author(s) 2021

\begin{abstract}
The assumption in the twin model that genotypic and environmental variables are uncorrelated is primarily made to ensure parameter identification, not because researchers necessarily think that these variables are uncorrelated. Although the biasing effects of such correlations are well understood, a method to estimate these parameters in the twin model would be useful. Here we explore the possibility of relaxing this assumption by adding polygenic scores to the (univariate) twin model. We demonstrate that this extension renders the additive genetic $(\mathrm{A})$-common environmental $(\mathrm{C})$ covariance $\left(\sigma_{\mathrm{AC}}\right)$ identified. We study the statistical power to reject $\sigma_{\mathrm{AC}}=0$ in the ACE model and present the results of simulations.
\end{abstract}

Keywords Classical twin design $\cdot$ Polygenic risk scores $\cdot$ A-C covariance $\cdot$ Identification $\cdot$ Statistical power

\section{Introduction}

The classical twin design (CTD; Eaves et al. 1978; Jinks and Fulker 1970) has been one of the most productive genetically informative designs in the study of human traits (Polderman et al. 2015). Twin studies have contributed greatly to our knowledge concerning genetic and environmental contributions to individual differences in psychological and medical traits, disease phenotypes and 'omics' variables (van Dongen et al. 2012). Multivariate and longitudinal extensions of the CTD have provided insights into the etiology of

Edited by David Evans.

Conor V. Dolan

c.v.dolan@vu.nl

1 Netherlands Twin Register, Department of Biological Psychology, Vrije Universiteit Amsterdam, Transitorium 2B03, Van der Boechorststraat 7, 1081 BT Amsterdam, The Netherlands

2 Virginia Institute for Psychiatric and Behavioral Genetics, Virginia Commonwealth University, 1-156, P.O. Box 980126, Richmond, VA 23298-0126, USA

3 Stanley Center for Psychiatric Disease, Broad Institute of MIT and Harvard, Cambridge, MA 02142, USA

4 Amsterdam Public Health Research Institute, Amsterdam Medical Centre, Amsterdam, The Netherlands

5 Analytic and Translational Genetics Unit, Massachusetts General Hospital, Boston, MA 02114, USA comorbidity and stability of traits and disorders. It is well understood that the correct interpretation of results based on the CTD depend on the tenability of the model assumptions (Eaves et al. 1977; Jinks and Fulker 1970; Plomin et al. 2016). The main assumptions of the CTD concern genotypeenvironment covariance (assumed to be absent), genotypeenvironment interaction (assumed to be absent), the equal environment assumption (environment does not cause larger resemblance in $\mathrm{MZ}$ than in $\mathrm{DZ}$ twins), and parental mating (assumed to be random, or that parental resemblance is due to social homogamy rather than phenotypic assortment). Given these assumptions, the results from the CTD can provide unbiased estimates of additive genetic (A), unshared environmental (E), and common environmental (C) and dominance (D) variance components. The effect of violations of these assumptions are well understood (Verhulst and Hatemi 2013; Purcell 2002; Keller et al. 2010), so that estimates of variance components obtained in the twin model may be interpreted in the light of possible model violations.

Many papers have been devoted to the detection and accommodation of model violations, either within the CTD (e.g., Purcell 2002; Molenaar et al. 2012; Eaves and Erkanli 2003; Carey 1986; Dolan et al. 2014; Beam and Turkheimer 2013), or in extended designs (e.g., Plomin et al. 1985; Narusyte et al. 2008; Neale and Fulker 1984; Fulker 1988; D'Onofrio et al. 2003; Keller et al. 2009; Heath et al. 1985; Maes et al. 2006). The aim of the present paper is to demonstrate that the incorporation of polygenic risk scores 
(PRSs) in the classical twin design allows one to estimate the covariance between $\mathrm{A}$ and $\mathrm{C}\left(\sigma_{\mathrm{AC}}\right)$. In the study of childhood intelligence, $\sigma_{\mathrm{AC}}>0$ is considered plausible, stemming from a process of cultural transmission (Keller et al. 2009; Fulker 1988), which gives rise to passive genotype-environment covariance in children (Plomin et al. 1977; Scarr and McCartney 1983, Knafo and Jaffee 2013; Kendler 2011; Rutter and Silberg 2002).

Measured genetic variables have been incorporated in genetically informative designs with various aims, apart from the gene finding of traditional linkage or combined linkage-association analysis (e.g., Fulker et al. 1999; Neale 2000). For instance, van den Oord and Snieder (2002) presented an extended twin model with measured genetic variables to test association in the presence of population stratification and to test causal relationships. Neale et al. (2000) partitioned variation in serum APOE levels into that associated with the APOE locus and residual genetic variance. In a study of attention problems, van Beijsterveldt et al. (2011) incorporated measured candidate gene information on SNPs in the serotonergic, dopaminergic system and the BDNF gene. The effect of SNPs was tested on a latent factor that summarized multiple assessments of attention problems across childhood. Minică et al. (2018) presented an integration of the CTD and Mendelian randomization method, in which PRSs feature as genetic instruments.

The use of measured genetic information specifically to study genotype-environment covariance is relatively new. Bates et al. (2018) and Kong et al. (2018) proposed the use of polygenic scores based on transmitted and nontransmitted alleles from parents to offspring to detect the effects of non-transmitted alleles on phenotype outcomes in their children. Warrington et al. (2018) used structural equation modeling to determine the fetal and maternal effects of measured genetic variants on birthweight, thus revealing genotype-environment covariance. Cheesman et al. (2020) applied PRSs in an adoption design to detect (passive) geneenvironment correlation in educational attainment. Selzam et al. (2019) used PRSs measured in DZ twin pairs to demonstrate the presence of gene-environment correlation for cognitive abilities, and the mediating role of social economic status therein. Wertz et al. (2018) used PRSs in a parent and offspring design to demonstrate the gene-environment correlation originating in parental behavior.

The present aim is to incorporate PRSs in the twin design with the aim of estimating A-C covariance. This approach allows us to determine the presence of A-C covariance, but sheds no light on the process that gave rise to the A-C covariance. For instance, the A-C covariance may be due to active (e.g., niche picking), passive (e.g., cultural transmission) or evocative processes (Plomin et al. 1977). The outline of this paper is as follows. First, we present the classical twin model, and the model extended with PRSs.
Second, given the model for PRSs in MZ and DZ twins, we address the issues of identification and statistical power. Third, we present the results of a small simulation to determine the effects of using estimated weights in calculating PRSs (i.e., the standard procedure) in comparison to exact known weights.

\section{The Twin Model with Polygenic Risk Scores: A-C Covariance}

Let $\mathrm{Ph}$ denote the phenotype of interest, and let $\mathrm{GV}_{\mathrm{k}}$ denote the k-th genetic variant $(\mathrm{GV})$ contributing to the variance of $\mathrm{Ph}$, where $\mathrm{k}=1 \ldots \mathrm{K}$, and $\mathrm{K}$ is the number of GVs. We limit our presentation to diallelic GVs (e.g., SNPs) with additive effects (additively coded, e.g., 0,1 , or 2). The phenotype $\mathrm{Ph}$ is modeled as follows:

$\mathrm{Ph}=\mathrm{b}_{0}+\sum_{k=1}^{K} b_{k} \mathrm{GV}_{\mathrm{ki}}+\mathrm{C}_{\mathrm{i}}+\mathrm{E}_{\mathrm{i}}$,

where $b_{0}$ is the intercept, $b_{k}$ is the $k$-th regression coefficient, subscript $\mathrm{i}$ denotes person, and $\mathrm{E}$ and $\mathrm{C}$ represent unshared and shared environmental factor scores of individual i. In the classical twin model, under the assumptions mentioned in the introduction, the variance of $\mathrm{Ph}$ is decomposed, in the ACE model, into the components $\sigma_{\mathrm{A}}^{2}, \sigma_{\mathrm{C}}^{2}$, and $\sigma_{\mathrm{E}}^{2}$ :

$\sigma_{\mathrm{Ph}}^{2}=\sigma_{\mathrm{A}}^{2}+\sigma_{\mathrm{C}}^{2}+\sigma_{\mathrm{E}}^{2}$.

The additive genetic variance equals the sum of the contributions of the individual GVs and their covariances $\left(\sigma_{\mathrm{GVk}, \mathrm{GVl}}\right)$ attributable to linkage disequilibrium:

$\sigma_{\mathrm{A}}^{2}=\sum_{\mathrm{k}=1}^{\mathrm{K}} \mathrm{b}_{\mathrm{k}}^{2} \sigma_{\mathrm{GVk}}^{2}+\sum_{\mathrm{k}=1}^{\mathrm{K}} \sum_{\mathrm{l}=1, \mathrm{l} \neq \mathrm{k}}^{\mathrm{K}} \mathrm{b}_{\mathrm{k}} \mathrm{b}_{1} \sigma_{\mathrm{GVk}, \mathrm{GVl}}$

Given $\sigma_{\mathrm{AC}} \neq 0$, we have (assuming no AE covariance)

$\sigma_{\mathrm{Ph}}^{2}=\sigma_{\mathrm{A}}^{2}+\sigma_{\mathrm{C}}^{2}+\sigma_{\mathrm{E}}^{2}+2 \sigma_{\mathrm{AC}}$,

where $\sigma_{\mathrm{AC}}$ is the covariance of $\mathrm{A}$ and $\mathrm{C}$. In this model, the parameter $\sigma_{\mathrm{AC}}$ is not identified. If we assume $\sigma_{\mathrm{AC}}=0$, while in truth $\sigma_{\mathrm{AC}}>0$, the variance $\sigma_{\mathrm{C}}^{2}$ is biased in the twin model, as $\sigma_{\mathrm{AC}}$ acts as $\mathrm{C}$, thus inflating the estimate of $\sigma^{2}{ }_{\mathrm{C}}$ in the standard ACE model (see Purcell 2002; Verhulst and Hatemi 2013). If in truth, $\sigma_{\mathrm{AC}}<0$, the $\mathrm{MZ}$ and $\mathrm{DZ}$ twin correlations suggest the presence of dominance variance (D).

Given estimates of the regression coefficients $\left(b_{k}\right)$ obtained in independent genome-wide association studies (GWASs), the PRS can be calculated $\sum_{\mathrm{l}=1}^{\mathrm{L}} \mathrm{b}_{1} \mathrm{GV}_{\mathrm{li}}$ (Purcell et al. 2009; Evans et al. 2009; Dudbridge 2013), where the set of L GVs is a subset of the K GVs. The set of L GVs may be chosen on the basis of the $\mathrm{p}$ value of the individual GVs or other considerations. Let the PRS equal $\mathrm{p}^{*} \mathrm{~A}_{\mathrm{p}}$, with variance $\mathrm{p}^{2 *} \sigma_{\text {Ap }}^{2}$. The scaling parameter $\mathrm{p}$ accommodates the 
fact that the phenotype $\mathrm{Ph}$ and the PRS are not measured on the same scale. Let $\mathrm{A}_{\mathrm{q}}$ denote the residual additive genetic variable. The model is now:

$\mathrm{PRS}_{\mathrm{i}}=\mathrm{p} \mathrm{A}_{\mathrm{pi}}$

$\mathrm{P}_{\mathrm{Phi}}=\mathrm{b}_{0}+\mathrm{A}_{\mathrm{pi}}+\mathrm{A}_{\mathrm{qi}}+\mathrm{C}_{\mathrm{i}}+\mathrm{E}_{\mathrm{i}}$,

The variance decomposition of the additive genetic variable $\mathrm{A}$ and the phenotype $\mathrm{Ph}$ are:

$\sigma_{\mathrm{PRS}}^{2}=\mathrm{p}^{2} \sigma_{\mathrm{Ap}}^{2}$

$\sigma_{\mathrm{A}}^{2}=\sigma_{\mathrm{Ap}}^{2}+\sigma_{\mathrm{Aq}}^{2}+2 \sigma_{\mathrm{ApAq}}$

$\sigma_{\mathrm{Ph}}^{2}=\sigma_{\mathrm{Ap}}^{2}+\sigma_{\mathrm{Aq}}^{2}+\sigma_{\mathrm{C}}^{2}+\sigma_{\mathrm{E}}^{2}+2 \sigma_{\mathrm{AC}}$,

where $\sigma_{\mathrm{AC}}=\sigma_{\mathrm{ApC}}+\sigma_{\mathrm{AqC}}$. The parameters $\sigma_{\mathrm{ApC}}$ and $\sigma_{\mathrm{AqC}}$ are the covariances of $\mathrm{A}_{\mathrm{p}}$ and $\mathrm{C}$ and of $\mathrm{A}_{\mathrm{q}}$ and $\mathrm{C}$, respectively. The parameter $\sigma_{\mathrm{ApAq}}$ is the covariance of the additive variables $\mathrm{A}_{\mathrm{p}}$ and $\mathrm{A}_{\mathrm{q}}$. We parameterize the covariance terms $\sigma_{\mathrm{ApC}}$ and $\sigma_{\mathrm{AqC}}$ as a function of the single covariance term $\sigma_{\mathrm{AC}}$ as follows. We derive the coefficient $\gamma_{\mathrm{p}}$ by tracing from $\mathrm{C}$ to $\mathrm{A}\left(\mathrm{C} \leftrightarrow \mathrm{A}\right.$ with coefficient $\left.\sigma_{\mathrm{AC}}\right)$, and then from $\mathrm{A}$ to $\mathrm{A}_{\mathrm{p}}$ $\left(A \rightarrow A_{p}\right)$ where $\gamma_{p}$ is the regression coefficient in the regression of $A_{p}$ on $A$. We do the same with $A_{q}$ using $\gamma_{q}$. The path diagram is shown in Fig. 1.

We thus obtain the constraints:

$\sigma_{\mathrm{ApC}}=\gamma_{\mathrm{p}} \sigma_{\mathrm{AC}}$,

$\sigma_{\mathrm{AqC}}=\gamma_{\mathrm{q}} \sigma_{\mathrm{AC}}$,

where
$\gamma_{\mathrm{p}}=\left\{\sigma_{\mathrm{Ap}}^{2}+\sigma_{\mathrm{ApAq}}\right\} / \sigma_{\mathrm{A}}^{2}$,

$\gamma_{\mathrm{q}}=\left\{\sigma_{\mathrm{Aq}}^{2}+\sigma_{\mathrm{ApAq}}\right\} / \sigma_{\mathrm{A}}^{2}$.

Note that $\sigma_{\mathrm{AC}}=\sigma_{\mathrm{ApC}}+\sigma_{\mathrm{AqC}}$, as $\gamma_{1}+\gamma_{2}=1$. At this point two comments are in order. First, it is not possible to estimate both the scaling parameter $\mathrm{p}$ and the parameter $\sigma_{\mathrm{ApAq}}$. We therefore set $\sigma_{\mathrm{ApAq}}$ to equal zero. Given this identifying constraint, $\gamma_{\mathrm{p}}=\sigma_{\mathrm{Ap}}^{2} / \sigma_{\mathrm{A}}^{2}$ and $\gamma_{\mathrm{q}}=\sigma_{\mathrm{Aq}}^{2} / \sigma_{\mathrm{A}}^{2}$. We demonstrate below that the constraint $\sigma_{\mathrm{ApAq}}=0$ has no bearing on the likelihood ratio test of $\sigma_{\mathrm{AC}}=0$, or on the maximum likelihood estimates of $\sigma_{\mathrm{AC}}, \sigma_{\mathrm{A}}^{2}$, and $\sigma_{\mathrm{C}}^{2}$. Second, we recognize that if $\sigma_{\mathrm{AC}} \neq 0$, the PRS weights $\left(\mathrm{b}_{1}\right)$ obtained in meta-analyses of the results of independent GWASs, which are used to calculate the PRS, will be upwardly (downwardly) biased given $\sigma_{\mathrm{AC}}>0\left(\sigma_{\mathrm{AC}}<0\right)$. This raises the question of whether this has any effect on the estimate of $\sigma_{\mathrm{AC}}$. We address this question below. The model is depicted in Fig. 2. We have parameterized this model in terms of variance components, i.e., we fixed the path coefficients terminating in the phenotype to one, and estimated the variance components $\left(\sigma_{\text {Ap }}^{2}\right.$, $\sigma_{\text {Aq }}^{2}, \sigma_{C}^{2}, \sigma_{\mathrm{E}}^{2}$, along with the parameter $\mathrm{p}$ ). One may also consider fixing the variance components to one, and estimating the path coefficients. However, this parameterization may complicate statistical tests of the variance components (see Verhulst et al. 2019, for details).

\section{Simulation I: Power}

In this model, the observed statistics are the $3 \times 3 \mathrm{MZ}$ (PRS, phenotype twin 1 , phenotype twin 2) and the $4 \times 4 \mathrm{DZ}$ (PRS1, PRS2, phenotype twin 1, phenotype twin 2) covariance matrices ( $\Sigma_{\mathrm{MZ}}$ and $\Sigma_{\mathrm{DZ}}$, respectively), and the 3- and

Fig. 1 The covariance between $\mathrm{C}$ and $\mathrm{A}_{\mathrm{p}}$ and $\mathrm{A}_{\mathrm{q}}$ are derived as $\sigma_{\mathrm{AC}} \gamma_{\mathrm{p}}$ and $\sigma_{\mathrm{AC}} \gamma_{\mathrm{q}}$, respectively, where $\gamma_{\mathrm{p}}=\sigma_{\mathrm{Ap}}^{2} / \sigma_{\mathrm{A}}^{2}$ and $\gamma_{\mathrm{q}}=\sigma_{\mathrm{Aq}}^{2} / \sigma_{\mathrm{A}}^{2}$

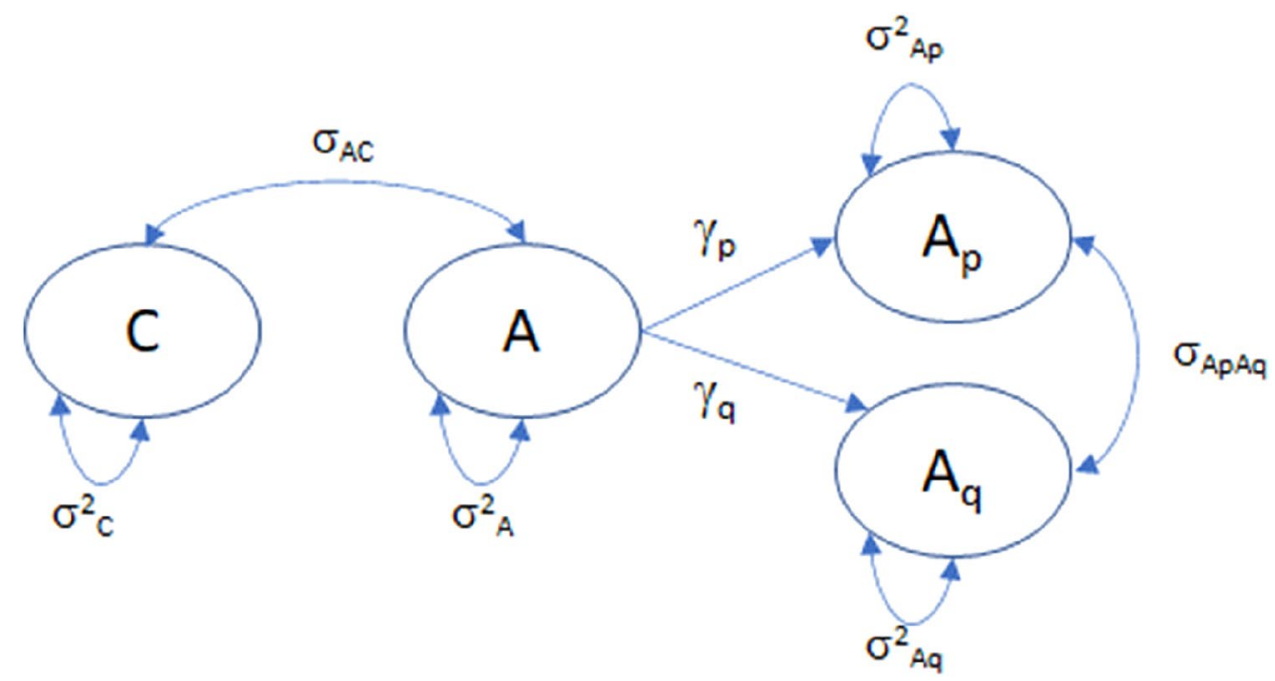




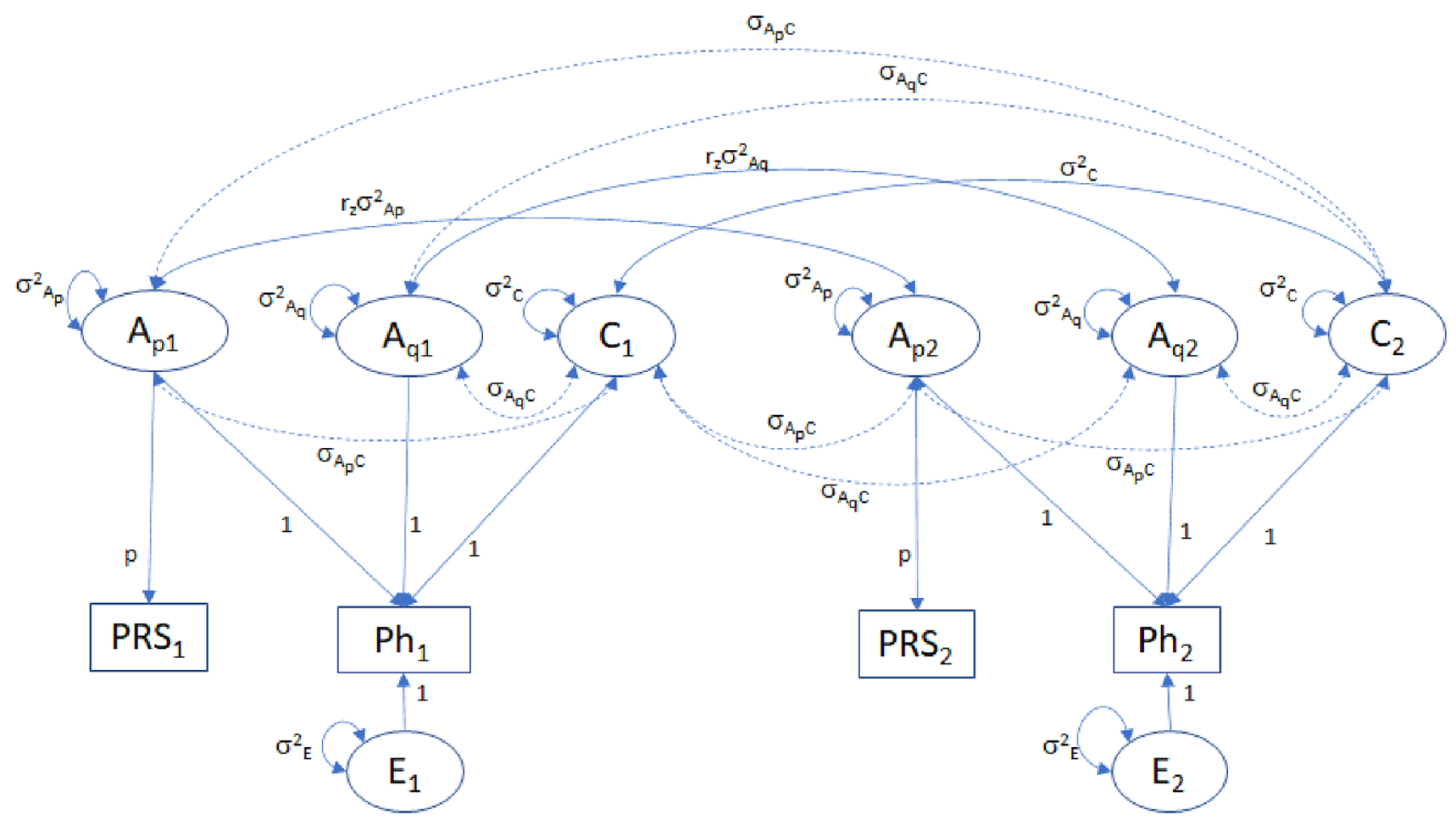

Fig. 2 ACE twin model with PRSs, including A-C covariances $\sigma_{\mathrm{ApC}}$ and $\sigma_{\mathrm{AqC}}$ (dashed double headed arrows). This is the model in DZ twins (i.e., $r_{z}=0.5$ ). The covariance between $A_{p}$ and $A_{q}$ is fixed

4-dimensional mean vectors. The MZ covariance matrix $\Sigma_{\mathrm{MZ}}$ is $3 \times 3$, as MZ twins, being genetically identical, have identical polygenic scores. We do not consider the mean structure of the phenotype data beyond noting that we adopt the standard (testable) assumptions that the means are equal over twins within a pair and over zygosity. Let the vector $\boldsymbol{\theta}$ contain the six parameters of the covariance structure model:

$\boldsymbol{\theta}=\left[\begin{array}{llllll}\mathrm{p} & \sigma_{\mathrm{Ap}}^{2} & \sigma_{\mathrm{Aq}}^{2} & \sigma_{\mathrm{C}}^{2} & \sigma_{\mathrm{E}}^{2} & \sigma_{\mathrm{AC}}^{2}\end{array}\right]$.

The vector $\boldsymbol{\theta}$ does not include $\sigma_{\mathrm{ApC}}$ and $\sigma_{\mathrm{AqC}}$ explicitly, because these parameters depend on the parameters $\sigma_{\mathrm{Ap}}^{2}$, $\sigma_{\text {Aq }}^{2}$, and the total covariance $\sigma_{\mathrm{AC}}$, as shown above. We evaluated local identification numerically using the OpenMx function mxCheckIdentification (written by Michael Hunter). The model is locally identified if the Jacobian matrix, $\mathbf{J}(\boldsymbol{\theta})$, is full column rank (Bekker et al. 1994). The Jacobian matrix contains the first-order derivatives of the non-redundant elements in the matrices $\Sigma_{\mathrm{MZ}}(\boldsymbol{\theta})$ and $\Sigma_{\mathrm{DZ}}(\boldsymbol{\theta})$ with respect to the parameters in $\boldsymbol{\theta}$. Given $6+10$ elements in $\Sigma_{\mathrm{MZ}}(\boldsymbol{\theta})$ and $\Sigma_{\mathrm{DZ}}(\boldsymbol{\theta})$, and 6 parameters $\mathrm{J}(\boldsymbol{\theta})$ is a $16 \times 6$ matrix. The mxCheckIdentification function is convenient as it does the necessary calculations automatically, and can be applied directly to the OpenMx script that one uses to fit the model.

Having established local identification, we proceeded to address the question of resolution by considering the to zero, but, as demonstrated in the text, this has no bearing on the derived estimate of the total A, C covarianc $\left(\sigma_{\mathrm{A}, \mathrm{C}}\right)$

statistical power to reject $\sigma_{\mathrm{AC}}=0$ given various parameter settings. We used exact data simulation (van der Sluis, et al. 2008), which is equivalent to analyzing the expected (true) covariance matrices. We used normal theory maximum likelihood estimation throughout, and based our power calculations on the non-centrality parameter (NCP) associated with the (non-central) chi-square distribution (Martin et al. 1978). Given exact data simulation, the NCP equals the loglikelihood ratio (LLR) test of $\sigma_{\mathrm{AC}}=0$. We used the OpenMx library (Boker et al. 2011; Neale et al. 2016) in the $\mathrm{R}$ program ( $\mathrm{R}$ Core Team 2018), and we used $\mathrm{R}$ for data simulation, and power calculations. In the power analyses, we set the $\mathrm{MZ}$ and DZ sample sizes equal $(\mathrm{Nmz}=1000, \mathrm{Ndz}=1000)$, and we report the power given $\mathrm{Nmz}=\mathrm{Ndz}=1000$, and the required sample sizes to achieve a power of 0.80 , given $\alpha=0.05$.

\section{Results I}

The numerical check of model identification demonstrated that the model is locally identified, bearing in mind that we have set $\sigma_{\mathrm{ApAq}}=0$. That is, given the $3 \times 3 \mathrm{MZ}$ and the $4 \times 4$ DZ phenotypic covariance matrices, $\Sigma_{\mathrm{MZ}}(\boldsymbol{\theta})$ and $\Sigma_{\mathrm{DZ}}(\boldsymbol{\theta})$, we can obtain unique estimates of the six parameters $\mathrm{p}, \sigma_{\text {Ap }}^{2}$, $\sigma_{\text {Aq }}^{2}, \sigma_{C}^{2}, \sigma_{E}^{2}$, and $\sigma_{A C}$. From the perspective of the path 
model (Fig. 2), the key to the identification is the covariance between the phenotype and the PRS, which does not depend on zygosity. This covariance equals $\mathrm{p}^{*} \sigma_{\mathrm{Ap}}{ }^{2}+\mathrm{p}^{*} \sigma_{\mathrm{ApC}}$ or $\mathrm{p}^{*} \gamma_{1}{ }^{*}\left(\sigma_{\mathrm{A}}{ }^{2}+\sigma_{\mathrm{AC}}\right)$, where $\mathrm{p}, \gamma_{1}$ and $\sigma_{\mathrm{A}}{ }^{2}$ are identified based on the phenotypic and PRS MZ and DZ twin covariances. Table 1 contains the results of the power study. This table includes the 16 parameter settings and the power to reject $\sigma_{\mathrm{AC}}=0$.

Table 1 contains the proportions of genetic and phenotypic variance explained by the PRS ( $p r \mathrm{PRS}$ and $p r \mathrm{Ph}$ in Table 1). These range from 0.2 to 0.4 ( $p r P R S)$ and 0.050 to $0.177(p r \mathrm{Ph})$. The correlation between $\mathrm{A}$ and $\mathrm{C}\left(\mathrm{r}_{\mathrm{AC}}\right)$ was chosen to equal 0.2 or 0.3 . In addition to this correlation, we express the $\sigma_{\mathrm{AC}}$ effect size as the proportion $\left(2 \sigma_{\mathrm{AC}}\right) / \sigma_{\mathrm{Ph}}^{2}$ (i.e., $p r 2 \sigma_{\mathrm{AC}}$ in Table 1), where $\sigma_{\mathrm{Ph}}^{2}=\sigma_{\mathrm{A}}^{2}+\sigma_{\mathrm{C}}^{2}+\sigma_{\mathrm{E}}^{2}+2 \sigma_{\mathrm{AC}}$. This proportion ranges from 0.088 to 0.189 . The proportion of A variance is $\sim 0.26$ or $\sim 0.40$; the proportion of $C$ variance is $\sim 0.18$ or $\sim 0.25$, and the proportion of $\mathrm{E}$ variance varies between 0.09 and 0.44 ). The settings, which are limited, were chosen merely to identify some circumstance in which the power to reject $\sigma_{\mathrm{AC}}=0$ is acceptable, given the present sample sizes.
The greatest power is obtained in settings 8,14 , and 16: 0.906 (8), 0.793 (14), and 0.950 (16). Here, the PRS accounts for $10.1 \%$ (8), $16.8 \%$ (14), and $16.2 \%$ (16) of the phenotypic variance, and $2 \sigma_{\mathrm{AC}}$ accounts for $15.3 \%$ (8), $15.9 \%$ (14), and $18.9 \%$ (16) of the phenotypic variance. We see the lowest power given settings $1(0.216)$ and 9 (0.238). Unsurprisingly, these are associated with relative low values of $p r 2 \sigma_{\mathrm{AC}}(8.8 \%$ and $11.2 \%)$ and $p r \mathrm{Ph}(5.4 \%$ and $8.8 \%)$. The relative contributions of $p r 2 \sigma_{\mathrm{AC}}$ and $p r \mathrm{Ph}$ to the power are apparent in the correlations of these with the power: 0.71 and 0.53 , respectively. Regressing the power on these parameters, we found that they explain $65 \%$ of the variance in power $\left(\beta p r 2 \sigma_{\mathrm{AC}}: 0.625\right.$ and $\beta p r \mathrm{Ph}$ 0.400 ). Both are important, but the contribution of $p r 2 \sigma_{\mathrm{Ac}}$ to the power is greater. The comparison of the $\sigma^{2}{ }_{\mathrm{A}}=0.3$ and the $\sigma_{\mathrm{A}}^{2}=0.5$ conditions show that the magnitude of $\sigma^{2}{ }_{A}$ does not greatly influence the power. In terms the ratio of the $\mathrm{N}$ (power $=0.80$ ) are about 1.1-1.2 (favoring the $\sigma_{\mathrm{A}}^{2}=0.5$ conditions). Finally, to determine the effect of the sign of $\sigma_{\mathrm{AC}}$, we repeated the power analysis with $\mathrm{r}_{\mathrm{AC}}$ set to equal -0.2 or -0.3 , and all other parameters unchanged. Figure 3 displays the plot of the power given positive and negative $r_{A C}$. We note that the difference in power is small suggesting that the sign of rAC is unimportant in calculating power.
Table 1 Statistical power to reject the null hypothesis that $\mathrm{A}-\mathrm{C}$ covariance is zero $($ alpha $=0.05)$

\begin{tabular}{lllllllllllll}
\hline & $p r \mathrm{PRS}$ & $p r \mathrm{Ph}$ & $\sigma_{\mathrm{A}}^{2}$ & $\sigma_{\mathrm{C}}^{2}$ & $\sigma_{\mathrm{E}}^{2}$ & $\sigma_{\mathrm{AC}}$ & $\mathrm{r}_{\mathrm{AC}}$ & $\sigma_{\mathrm{Ph}}^{2}$ & $p r 2 \sigma_{\mathrm{AC}}$ & Power & $\mathrm{N}(0.80)$ \\
\hline 1 & 0.2 & 0.054 & $0.3(0.27)$ & $0.2(0.18)$ & $0.5(0.45)$ & 0.048 & 0.2 & 1.09 & 0.088 & 0.216 & 11,420 \\
2 & 0.2 & 0.052 & $0.3(0.26)$ & $0.2(0.17)$ & $0.5(0.43)$ & 0.073 & 0.3 & 1.14 & 0.128 & 0.415 & 5158 \\
3 & 0.2 & 0.053 & $0.3(0.27)$ & $0.3(0.26)$ & $0.4(0.36)$ & 0.060 & 0.2 & 1.12 & 0.107 & 0.323 & 6971 \\
4 & 0.2 & 0.050 & $0.3(0.25)$ & $0.3(0.25)$ & $0.4(0.34)$ & 0.090 & 0.3 & 1.18 & 0.153 & 0.606 & 3161 \\
5 & 0.4 & 0.109 & $0.3(0.27)$ & $0.2(0.18)$ & $0.5(0.45)$ & 0.048 & 0.2 & 1.09 & 0.088 & 0.402 & 5352 \\
6 & 0.4 & 0.104 & $0.3(0.26)$ & $0.2(0.17)$ & $0.5(0.43)$ & 0.073 & 0.3 & 1.14 & 0.128 & 0.724 & 2408 \\
7 & 0.4 & 0.107 & $0.3(0.27)$ & $0.3(0.26)$ & $0.4(0.36)$ & 0.060 & 0.2 & 1.12 & 0.107 & 0.595 & 3241 \\
8 & 0.4 & 0.101 & $0.3(0.25)$ & $0.3(0.25)$ & $0.4(0.34)$ & 0.090 & 0.3 & 1.18 & 0.153 & 0.906 & 1462 \\
9 & 0.2 & 0.088 & $0.5(0.44)$ & $0.2(0.18)$ & $0.3(0.27)$ & 0.063 & 0.2 & 1.12 & 0.112 & 0.238 & 10,107 \\
10 & 0.2 & 0.084 & $0.5(0.42)$ & $0.2(0.17)$ & $0.3(0.25)$ & 0.094 & 0.3 & 1.18 & 0.159 & 0.455 & 4594 \\
11 & 0.2 & 0.086 & $0.5(0.43)$ & $0.3(0.26)$ & $0.2(0.17)$ & 0.077 & 0.2 & 1.15 & 0.134 & 0.362 & 6084 \\
12 & 0.2 & 0.081 & $0.5(0.40)$ & $0.3(0.24)$ & $0.2(0.16)$ & 0.116 & 0.3 & 1.23 & 0.189 & 0.661 & 2784 \\
13 & 0.4 & 0.177 & $0.5(0.44)$ & $0.2(0.18)$ & $0.3(0.26)$ & 0.063 & 0.2 & 1.12 & 0.112 & 0.465 & 4481 \\
14 & 0.4 & 0.168 & $0.5(0.42)$ & $0.2(0.17)$ & $0.3(0.25)$ & 0.094 & 0.3 & 1.18 & 0.158 & 0.794 & 2028 \\
15 & 0.4 & 0.173 & $0.5(0.43)$ & $0.3(0.26)$ & $0.2(0.17)$ & 0.077 & 0.2 & 1.15 & 0.133 & 0.682 & 2650 \\
16 & 0.4 & 0.162 & $0.5(0.41)$ & $0.3(0.24)$ & $0.2(0.16)$ & 0.116 & 0.3 & 1.23 & 0.188 & 0.950 & 1206 \\
\hline
\end{tabular}

Given $\sigma_{\mathrm{A}}^{2}=\sigma_{\mathrm{Ap}}^{2}+\sigma_{\mathrm{Aq}}^{2}, p r$ PRS equals $\sigma_{\mathrm{Ap}}^{2} / \sigma_{\mathrm{A}}^{2}$, i.e., the proportion of additive genetic variance attributable to the PRS, and $p r \mathrm{Ph}$ is the proportion of phenotypic variance attributable to the PRS, $\sigma^{2}{ }_{\mathrm{Ap}} / \sigma_{\mathrm{Ph}}^{2} ; \mathrm{r}_{\mathrm{AC}}$ and $\sigma_{\mathrm{AC}}$ are the correlation and covariance of $\mathrm{A}$ and $\mathrm{C}, \sigma_{\mathrm{Ph}}^{2}$ is the phenotypic variance; $p r 2 * \sigma_{\mathrm{AC}}$ is the proportion of phenotypic variance due to $2 * \sigma_{\mathrm{AC}}$

The standardized A, C, E variance components are given in parentheses. For instance, in setting 16, the raw variance is $0.5+0.3+0.2+0.116 * 2=1.23$, and the standardized variance is $0.41+0.24+0.16+0.188=\sim$ 1

The power is given for $\mathrm{Nmz}=\mathrm{Ndz}=1000$, given $\alpha=0.05 ; \mathrm{N}(0.80)$ is the sample size $(\mathrm{N}=\mathrm{Nmz}+\mathrm{Ndz}$, where $\mathrm{Nmz}=\mathrm{Ndz}$ ) associated with a power of 0.80 , given $\alpha=0.05$ 


\section{Simulation II: Bias and Type I Error Rate}

As noted above, the weights $\left(b_{1}\right)$ used to calculate the PRS are expected be biased upwards if $\sigma_{\mathrm{AC}}>0$. We investigated the effects of this in a simulation study. Specifically, we simulated data according to the nuclear twin family (NTF) design (Fulker 1988; Keller et al. 2009), which comprises MZ and DZ twins and their parents. This model includes cultural transmission, i.e., the direct contribution of the parental phenotype to the twin's environment (parameter $\mathrm{m}$ in the notation of Keller et al. 2009 notation). This contribution gives rise to a shared environmental variable ( $F$ in the notation of Keller et al. 2009), and to covariance between this variable $(\mathrm{F})$ and the additive genetic factor $(\mathrm{A}), \sigma_{\mathrm{AF}}$. In addition to the shared variance due to $\mathrm{F}$, the model includes a shared environmental variance term, due to shared influences other than cultural transmission. We denote this $\mathrm{C}^{*}$ to distinguish it from the $\mathrm{C}$ in the standard ACE model. The original NTF model accommodates phenotypic assortative mating. However, here we assume that mating is random. The MZ and DZ expected phenotypic covariance matrices are shown in Table 2. It is not possible to resolve $\mathrm{F}$ and $\mathrm{C}^{*}$ in the absence of parental phenotypes. Thus, in the standard ACE model and in the model with PRSs, we estimate a single shared environmental variance, $\sigma_{C}^{2}$ which actually equals $\sigma_{\mathrm{C}^{*}}^{2}+\sigma_{\mathrm{F}}^{2}$.

First, we considered the model without cultural transmission, i.e., cultural transmission parameter (m) was zero. This implies that $\sigma_{\mathrm{F}}^{2}$ and $\sigma_{\mathrm{AF}}$ are zero, as the parameter $\mathrm{m}$ is the source of the A-C covariance. However, we included

Table 2 The expected covariance matrices in simulations 1-3

\begin{tabular}{|c|c|c|}
\hline & MZ 1 & MZ 2 \\
\hline MZ 1 & $\sigma_{\mathrm{A}}^{2}+\sigma_{\mathrm{C}^{*}}^{2}+\sigma_{\mathrm{F}}^{2}+2 \sigma_{\mathrm{AF}}+\sigma_{\mathrm{E}}^{2}$ & $\sigma_{\mathrm{A}}^{2}+\sigma_{\mathrm{C}^{*}}^{2}+\sigma_{\mathrm{F}}^{2}+2 \sigma_{\mathrm{AF}}$ \\
\hline MZ 2 & $\begin{array}{l}\sigma_{\mathrm{A}}^{2}+\sigma_{\mathrm{C}^{*}}^{2}+\sigma_{\mathrm{F}}^{2}+2 \sigma_{\mathrm{AF}} \\
\mathrm{DZ} 1\end{array}$ & $\begin{array}{l}\sigma_{\mathrm{A}}^{2}+\sigma_{\mathrm{C}^{*}}^{2}+\sigma_{\mathrm{F}}^{2}+2 \sigma_{\mathrm{AF}}+\sigma_{\mathrm{E}}^{2} \\
\mathrm{DZ} 2\end{array}$ \\
\hline DZ 1 & $\sigma_{\mathrm{A}}^{2}+\sigma_{\mathrm{C}^{*}}^{2}+\sigma_{\mathrm{F}}^{2}+2 \sigma_{\mathrm{AF}}+\sigma_{\mathrm{E}}^{2}$ & $1 / 2 \sigma_{\mathrm{A}}^{2}+\sigma_{\mathrm{C}^{*}}^{2}+\sigma_{\mathrm{F}}^{2}+2 \sigma_{\mathrm{AF}}$ \\
\hline DZ 2 & $\begin{array}{l}1 / 2 \sigma_{\mathrm{A}}^{2}+\sigma_{\mathrm{C}^{*}}^{2}+\sigma_{\mathrm{F}}^{2}+2 \sigma_{\mathrm{AF}} \\
\sigma_{\mathrm{F}}^{2}=2 \mathrm{~m}^{2}\left(\sigma_{\mathrm{A}}^{2}+\sigma_{\mathrm{C}^{*}}^{2}+\sigma_{\mathrm{F}}^{2}+2 \sigma_{\mathrm{F}}\right. \\
\sigma_{\mathrm{AF}}=\left(\mathrm{m} \sigma_{\mathrm{A}}\right) /\left(1-\sigma_{\mathrm{F}} \mathrm{m}\right)\end{array}$ & $\begin{array}{l}\sigma_{\mathrm{A}}^{2}+\sigma_{\mathrm{C}^{*}}^{2}+\sigma_{\mathrm{F}}^{2}+2 \sigma_{\mathrm{AF}}+\sigma_{\mathrm{E}}^{2} \\
\left.\mathrm{AF}^{+}+\sigma_{\mathrm{E}}^{2}\right)=2 \mathrm{~m}^{2} \sigma_{\mathrm{Ph}}^{2}\end{array}$ \\
\hline
\end{tabular}

Parameter $\mathrm{m}$ is the regression coefficient in regression of parental phenotype on $\mathrm{F}$ in twins (shared environmental factor attributable to cultural transmission)

$\sigma_{\mathrm{F}}^{2}$ is shared environmental variance due to cultural transmission (see Keller et al. 2009, for the derivation)

$\sigma_{C^{*}}^{2}$ is shared environmental variance, not due to cultural transmission

$\sigma_{\mathrm{E}}^{2}$ is unshared environmental variance

$\sigma_{\mathrm{A}}^{2}$ additive genetic variance

$\sigma_{\mathrm{AF}}$ covariance of A and $\mathrm{F}$ (see Keller et al. 2009, for the derivation)

Note in fitting the model we estimate $\sigma^{2}$ (i.e., $\sigma_{\mathrm{F}}^{2}+\sigma_{\mathrm{C}^{*}}^{2}$ )
$\sigma_{C^{*}}^{2}>0$. Thus, there is shared (by the twins) environmental variance, but it is not due to cultural transmission. This model allows us to determine the Type I error rate associated with the test of $\sigma_{\mathrm{AC}}=0$. As an aside, in this simulation, the inclusion of $\sigma_{C^{*}}^{2}>0$ also allows us to establish the power to detect $\mathrm{C}$ variance in a twin model with PRS, in addition to checking the Type I error rate in test of $\sigma_{\mathrm{AC}}=0$. Second, we considered a model with cultural transmission, with $\mathrm{m}>0$, so that $\sigma_{\mathrm{AF}}>0$ and $\sigma_{\mathrm{F}}^{2}>0$. In this model we set $\sigma_{\mathrm{C}^{*}}^{2}$ to zero, so that there are no shared environmental influences other than those stemming from the cultural transmission. Third, we considered a model with cultural transmission $(m>0)$, so that $\sigma_{\mathrm{AF}}>0$ and $\sigma_{\mathrm{F}}^{2}>0$, and $\sigma_{\mathrm{C}^{*}}^{2}>0$. As mentioned, we cannot resolve $\sigma_{\mathrm{F}}^{2}$ and $\sigma_{\mathrm{C}^{*}}^{2}$, so we fitted a single shared environmental factor, representing $\mathrm{C}$ and $\mathrm{F}$. In summary, given $\sigma_{C}^{2}=\sigma_{F}^{2}+\sigma_{C^{*}}^{2}$, we have the following settings. Simulation 1: $\mathrm{m}=0, \sigma_{\mathrm{F}}^{2}=0, \sigma_{\mathrm{C}^{*}}^{2}>0, \sigma_{\mathrm{C}}^{2}=\sigma_{\mathrm{C}^{*}}^{2}, \sigma_{\mathrm{AC}}=\sigma_{\mathrm{AF}}=0$. Simulation 2: $\mathrm{m}>0, \sigma_{\mathrm{F}}^{2}>0, \sigma_{\mathrm{C}^{*}}^{2}=0, \sigma_{\mathrm{C}^{2}}^{2}=\sigma_{\mathrm{F}}^{2}, \sigma_{\mathrm{AC}}=\sigma_{\mathrm{AF}}$ and $\sigma_{\mathrm{AF}}>0$. Simulation 3: $\mathrm{m}>0, \sigma_{\mathrm{F}}^{2}>0, \sigma_{\mathrm{C}^{*}}^{2}>0$, $\sigma_{\mathrm{C}}^{2}=\sigma_{\mathrm{F}}^{2}+\sigma_{\mathrm{C}^{*}}^{2}, \sigma_{\mathrm{AC}}=\sigma_{\mathrm{AF}}$ and $\sigma_{\mathrm{AF}}>0$.

In each simulation study based on these three models, we carried out 500 replications. Each data set comprised genotypic and phenotypic data in parents and twins. The parental data were discarded, and the twin data were used to fit the model. The additive genetic variable comprised 100 uncorrelated diallelic genetic variants, of which 40 were used to calculate the PRS. We carried out the simulation twice: once with exact, unbiased PRS weights (i.e., the parameters $b$ in the expression $\mathrm{PRS}_{\mathrm{i}}=\sum_{\mathrm{l}=1}^{\mathrm{L}} \mathrm{b}_{1} \mathrm{GV}_{\mathrm{li}}$ ), and once with estimated weights $b$. We estimated the weights in independent data (not the data used to fit the actual model) by regressing the phenotype on the genetic variants. Given the absence of A-C covariance, the estimated weights are unbiased. In each replication the sample sizes were $\mathrm{N}=2000$ to estimate the parameter weights $\mathrm{b}$, and $\mathrm{Nmz}=1000$ and $\mathrm{Ndz}=1000$ (in total 2000 pairs) to fit the actual model. Parameter values and effect sizes are given in Table 3 . In simulations 1-3, the true values of $p r \mathrm{Ph}$ are $0.2,0.141$, and 0.147 , and the true values of $p r 2 \sigma_{\mathrm{A}, \mathrm{C}^{*}+\mathrm{F}}$ are $0.0,0.353$, and 0.368 , respectively.

In summary, the aims were (1) to establish that the Type 1 error rate was correct and (2) to investigate the effects, if any, of biased weights on the Type I error rate and the parameter estimates (bias), (3) to determine whether the presence of PRS, given zero A-C covariance, increases the power to detect $\mathrm{C}$ variance.

\section{Results II}

We first discuss the parameter estimates and then the loglikelihood ratio (LLR) test statistics. Table 3 contains the true parameter values and the mean and standard deviation of the parameter estimates based on the 500 replications. 
Table 3 Means and standard deviation of parameter estimates in simulation 1-3 based on 500 replications $(\mathrm{Nmz}=1000$; $\mathrm{Ndz}=1000)$

\begin{tabular}{|c|c|c|c|c|c|c|c|c|}
\hline & $\begin{array}{l}\mathrm{b} \\
\text { est }\end{array}$ & $\sigma_{\mathrm{Ap}}^{2}$ & $\sigma_{\mathrm{Aq}}^{2}$ & $\sigma_{C^{*}}^{2}$ & $\sigma_{F}^{2}$ & $\begin{array}{l}\sigma_{C}^{2}= \\
\sigma_{C^{*}}^{2}+\sigma_{F}^{2}\end{array}$ & $\sigma_{\mathrm{E}}^{2}$ & $\sigma_{\mathrm{A}, \mathrm{C}}$ \\
\hline \multicolumn{9}{|l|}{ Simulation 1} \\
\hline True & & 0.20 & 0.30 & 0.20 & $\mathbf{0}$ & 0.20 & 0.30 & 0.00 \\
\hline Mean & No & 0.199 & 0.298 & 0.197 & - & - & 0.301 & 0.003 \\
\hline s.d. & & 0.026 & 0.045 & 0.058 & - & - & 0.013 & 0.033 \\
\hline s.e.(mean) & & 0.0012 & 0.0020 & 0.0026 & & & 0.0006 & 0.0015 \\
\hline Mean & Yes & $0.184 *$ & $0.316^{*}$ & 0.199 & - & - & 0.300 & 0.001 \\
\hline s.d. & & 0.026 & 0.047 & 0.063 & - & - & 0.013 & 0.036 \\
\hline s.e.(mean) & & 0.0012 & 0.0021 & 0.0028 & & & 0.0006 & 0.0016 \\
\hline \multicolumn{9}{|l|}{ Simulation 2} \\
\hline True & & 0.20 & 0.30 & $\mathbf{0}$ & 0.091 & 0.091 & 0.30 & 0.125 \\
\hline Mean & No & 0.200 & 0.300 & - & 0.087 & - & 0.301 & 0.126 \\
\hline s.d. & & 0.026 & 0.047 & - & 0.078 & - & 0.013 & 0.037 \\
\hline s.e.(mean) & & 0.0012 & 0.0021 & & 0.0035 & & 0.0006 & 0.0017 \\
\hline Mean 2 & Yes & $0.189^{*}$ & $0.315^{*}$ & - & 0.090 & - & 0.300 & 0.124 \\
\hline s.d. & & 0.025 & 0.046 & - & 0.079 & - & 0.013 & 0.038 \\
\hline s.e.(mean) & & 0.0011 & 0.0021 & & 0.0035 & & 0.0006 & 0.0017 \\
\hline \multicolumn{9}{|l|}{ Simulation 3} \\
\hline True & & 0.20 & 0.30 & 0.20 & 0.108 & 0.308 & 0.30 & 0.125 \\
\hline Mean & No & 0.200 & 0.302 & - & - & 0.302 & 0.300 & 0.126 \\
\hline s.d. & & 0.026 & 0.045 & - & - & 0.077 & 0.013 & 0.039 \\
\hline s.e.(mean) & & 0.0012 & 0.0020 & & & 0.0034 & 0.0006 & 0.0017 \\
\hline Mean & Yes & $0.185^{*}$ & $0.320 *$ & - & - & 0.304 & 0.299 & 0.125 \\
\hline s.d. & & 0.026 & 0.050 & - & - & 0.087 & 0.013 & 0.041 \\
\hline s.e.(mean) & & 0.0012 & 0.0022 & & & 0.0039 & 0.0006 & 0.0018 \\
\hline \multicolumn{9}{|l|}{ Simulation $2^{\mathrm{a}}$} \\
\hline True & & 0.20 & 0.30 & $\mathbf{0}$ & 0.091 & 0.091 & 0.30 & 0.125 \\
\hline Mean & Yes & $0.189^{*}$ & $0.314^{*}$ & - & 0.095 & - & 0.299 & 0.122 \\
\hline s.d. & & 0.025 & 0.045 & - & 0.061 & - & 0.013 & 0.032 \\
\hline s.e.(mean) & & 0.0011 & 0.0020 & & 0.0027 & & 0.0006 & 0.0014 \\
\hline
\end{tabular}

Values shown in bold are the true parameter values

Simulation $2^{\mathrm{a}}$ : subject to constraints of positive definiteness of the $\mathrm{A}_{\mathrm{p}}-\mathrm{C}$ and $\mathrm{A}_{\mathrm{q}}-\mathrm{C}$ covariance matrices b est: weights for PRS estimated (yes), or fixed to true values (no)

Simulation 1: $\mathrm{r}(\mathrm{A}, \mathrm{F}+\mathrm{C})=0 ; \sigma_{\mathrm{Ph}}^{2}=0.20+0.30+0.20+0.30=1 ; \mathrm{r}(\mathrm{MZ})=0.70 \& \mathrm{r}(\mathrm{DZ})=0.45 ; p r \mathrm{PH}=0.2$; pr $2 \sigma_{\mathrm{AC}}=0.0$

Simulation 2: $\mathrm{r}(\mathrm{A}, \mathrm{F}+\mathrm{C})=0.125 / \mathrm{sqrt}(0.5 * 0.091)=0.586 ; \quad \sigma_{\mathrm{Ph}}^{2}=1.141 ; \mathrm{r}(\mathrm{MZ})=0.74 \quad \& \quad \mathrm{r}(\mathrm{DZ})=0.52$; $p r \mathrm{PH}=0.141 ; p r 2 \sigma_{\mathrm{AC}}=0.353$

Simulation 3: $\mathrm{r}(\mathrm{A}, \mathrm{F}+\mathrm{C})=0.125 / \operatorname{sqrt}\left(0.5^{*} 0.308\right)=0.318 ; \quad \sigma_{\mathrm{Ph}}^{2}=1.358 ; \mathrm{r}(\mathrm{MZ})=0.78 \quad \& \quad \mathrm{r}(\mathrm{DZ})=0.59$; $p r \mathrm{PH}=0.147 ; p r 2 \sigma_{\mathrm{AC}}=0.368$

*Deviation from true value is significant given $\alpha=0.01$

Note in fitting the model we estimated the single variance term $\sigma_{\mathrm{C}}^{2}$, which equals $\sigma_{\mathrm{F}}^{2}+\sigma_{\mathrm{C}^{*} \text {. In simula- }}^{2}$ tions $1, \sigma_{\mathrm{F}}^{2}$ is zero and $\sigma_{\mathrm{AC}}=0$; in simulation $2 \sigma_{\mathrm{C}^{*}}^{2}$ is zero, $\sigma_{\mathrm{AC}}>0$; in simulation $3, \sigma_{\mathrm{F}}^{2}>0, \sigma_{\mathrm{C}^{*}}^{2}>0$, and $\sigma_{\mathrm{AC}}>0$

In simulation 1, given exact PRS weights, the parameter estimates are unbiased, as expected. Given estimated PRS weights, the estimates of $\sigma_{\text {Ap }}^{2}$ and $\sigma^{2}{ }_{\text {Aq }}$ are biased: the mean values are 0.184 (underestimated; true 0.2) and 0.316 (overestimated; true: 0.3 ), respectively. The estimate of the covariance term $\sigma_{\mathrm{AC}}$ is unbiased: the mean value is 0.001 (true: $0.0)$. In simulation two, given exact weights, the parameter estimates are again unbiased, and given estimated PRS weights, the estimates of $\sigma^{2}$ Ap and $\sigma^{2}{ }_{\mathrm{Aq}}$ are again biased: the mean values are 0.189 (underestimated; true 0.2 ) and 0.315 (overestimated; true: 0.3), respectively. The estimate of $\sigma_{\mathrm{AC}}$ is unbiased: mean value 0.124 (true 0.125 ). Simulation three produced the same results as simulation two, in terms of parameter bias stemming from using estimated PRS weight. 
The main finding is that using estimated PRS weights results in biased estimates of the variance components $\sigma^{2}$ Ap and $\sigma_{\text {Aq }}^{2}$, but has little effect on the estimate of the covariance term $\sigma_{\mathrm{AC}}$.

Table 4 contains the results of the LLR tests. We tested the hypotheses $\sigma_{\mathrm{A}, \mathrm{C}}=0$, and $\sigma_{\mathrm{C}}^{2}=0$ given $\sigma_{\mathrm{A}, \mathrm{F}+\mathrm{C}}=0$ in the twin model with the PRSs. In addition, we tested the hypothesis $\sigma_{\mathrm{C}}^{2}=0$ in the standard univariate ACE model. The test of $\sigma_{C}^{2}=0$ is of interest in simulation 1 , as the comparison of $\sigma^{2}{ }_{C}=0$ given $\sigma_{\mathrm{A}, \mathrm{F}+\mathrm{C}}=0$ (in the full model) and hypothesis $\sigma_{C}^{2}=0$ in the standard univariate ACE model tell us whether the presence of PRSs helps to resolve C. The LLR statistic associated with the test of $\sigma_{\mathrm{A}, \mathrm{F}+\mathrm{C}}=0$ in simulation 1, where in truth $\sigma_{\mathrm{A}, \mathrm{F}+\mathrm{C}}=0$, should follow central chi2(1) distribution, which is characterized by a mean of 1 and a standard deviation of $\sqrt{ }(2)=1.414$. Given exact PRS weights, the mean and standard deviation of the LLR statistic are 0.970 and 1.423 (see Table 4). These do not differ from the expected

Table 4 Means and standard deviation of loglikelihood ratio tests simulation $1-3$ based on 500 replications $(\mathrm{Nmz}=1000 ; \mathrm{Ndz}=1000)$

\begin{tabular}{lcccc}
\hline & b est & $\sigma_{\mathrm{A}, \mathrm{C}}=0$ & $\begin{array}{l}\sigma^{2}{ }_{\mathrm{C}}=0 \\
\text { given } \sigma_{\mathrm{A}, \mathrm{C}}=0\end{array}$ & $\begin{array}{l}\sigma^{2}{ }_{\mathrm{C}}=0 \text { in } \\
\mathrm{ACE} \text { model }\end{array}$ \\
\hline Simulation 1 & & & & \\
Mean & No & $0.970^{\mathrm{a}}$ & 22.2 & 16.06 \\
sd & & 1.423 & 8.88 & 7.344 \\
Mean & Yes & $1.041^{\mathrm{a}}$ & 21.52 & 15.62 \\
sd & & 1.515 & 8.94 & 7.49 \\
Simulation 2 & & & & \\
Mean & No & 15.11 & 25.12 & 37.16 \\
sd & & 7.47 & 10.13 & 11.23 \\
Mean & Yes & 13.51 & 25.99 & 36.63 \\
sd & & 7.38 & 9.66 & 11.25 \\
Simulation 3 & & & & \\
Mean & No & 13.48 & 78.87 & 78.98 \\
sd & & 7.16 & 15.40 & 15.96 \\
Mean & Yes & 11.96 & 74.59 & 78.43 \\
sd & & 6.65 & 16.93 & 17.05 \\
Simulation 2 & & & & 36.66 \\
Mean & Yes & 13.92 & 25.54 & 12.11 \\
sd & & 7.49 & 9.92 & \\
\hline
\end{tabular}

Means are the mean of the 1-df likelihood ratio test

b est: weights for PRS estimated (yes), or fixed to true values (no)

Simulation $\quad 1: \quad \mathrm{r}(\mathrm{A}, \mathrm{C})=0 ; \quad \sigma_{\mathrm{Ph}}^{2}=0.20+0.30+0.20+0.30=1 ;$ $\mathrm{r}(\mathrm{MZ})=0.70 \& \mathrm{r}(\mathrm{DZ})=0.45 ; p r \mathrm{PH}=0.2 ; p r 2 \sigma_{\mathrm{AC}}=0.0$

Simulation 2: r(A, C) $=0.125 / \operatorname{sqrt}\left(0.5^{*} 0.091\right)=0.586 ; \sigma_{\mathrm{Ph}}^{2}=1.141$; $\mathrm{r}(\mathrm{MZ})=0.74 \& \mathrm{r}(\mathrm{DZ})=0.52 ; p r \mathrm{PH}=0.141 ; p r 2 \sigma_{\mathrm{AC}}=0.353$

Simulation 3: $\mathrm{r}(\mathrm{A}, \mathrm{C})=0.125 / \mathrm{sqrt}\left(0.5^{*} 0.308\right)=0.318 ; \sigma_{\mathrm{Ph}}^{2}=1.358$; $\mathrm{r}(\mathrm{MZ})=0.78 \& \mathrm{r}(\mathrm{DZ})=0.59 ; p r \mathrm{PH}=0.147 ; p r 2 \sigma_{\mathrm{AC}}=0.368$

${ }^{\text {a }}$ Expected mean value $=1$, expected stdev $=\sqrt{ } 2=1.414$

${ }^{b}$ Subject to constraints of positive definiteness of the $A_{p}-C$ and $A_{q}-C$ covariance matrices values of 1 and $\sqrt{ } 2$ (LLR test: $0.27, d f=2, p=0.87$ ). The Type I error rate equaled 0.049 (CI95: 0.032-0.072). Given estimated weights, the values are 1.041 and 1.515 . While these do not appear to deviate from the expected values (LLR test: $5.18, \mathrm{df}=2, \mathrm{p}=0.075$ ), the variance is larger (1.515 vs. 1.414 ), as is the Type I error rate: 0.063 (CI95: 0.043-0.088). In terms of the mean LLR test, we note that the test of $\sigma_{\mathrm{C}}{ }^{2}=0$ is more powerful in the full model (given $\sigma_{\mathrm{A}, \mathrm{C}}=0$ ) than in the standard univariate ACE twin model. With exact PRS weights, the mean LLR test statistics equal 22.2 (with PRSs) and 16.06 (standard ACE model), and with estimated PRS weight, 21.5 and 15.6.

The results of simulation 2 and 3 are comparable. The test of $\sigma_{\mathrm{AC}}=0$ suffers slightly given estimated PRS weights: the mean LLR test statistics equal 15.10 and 13.5 (simulation 2 ) and 13.48 and 11.96 (simulation 3 ). The effect of the test of $\sigma_{\mathrm{C}}^{2}=0$ given $\sigma_{\mathrm{AC}}=0$ is slight (in simulation 3: $78.8 \mathrm{vs}$ 74.6). We note that the test of $C$ in the standard twin model appears to be more powerful. However, given $\sigma_{\mathrm{AC}}>0$, this is a combined test of $\sigma_{\mathrm{C}}^{2}=0$ and $\sigma_{\mathrm{AC}}=0$.

In simulation 2, we set $\sigma_{\mathrm{C}^{*}}^{2}=0$ and $\sigma_{\mathrm{F}}^{2}=0.091$ (6.4\% of the phenotypic variance). This relatively low value does not rule out a considerable contribution of $\sigma_{\mathrm{AC}}$ to the phenotypic variance $(35 \%)$. The true twin correlations in the simulation $2\left(\mathrm{r}_{\mathrm{MZ}}=0.74, \mathrm{r}_{\mathrm{DZ}}=0.52\right)$ suggest a considerable contribution of $\mathrm{C}(\sim 30 \%)$. This implies that (1) substantial $\mathrm{C}$ in the classical twin model may be mainly due to A-C covariance, while (2) the $\mathrm{C}$ variance, which in simulation 2 comprised only $\sigma_{\mathrm{F}}^{2}$, may be small. Given that this variance may be small, its estimate may, given the present variance component parameterization, assume negative values. Indeed, in simulation 2 , we encountered a negative variance component estimate in about $11 \%$ (exact PRS weights) and 13\% (estimated weights) of the replications (we did not remove these cases in calculating the results in Tables 3 and 4 to avoid the bias caused by truncating the distribution of the parameters to the admissible solutions). The problem of negative variance can be solved by imposing the constraint that the $2 \times 2$ covariance matrix of $A_{p}$ and $C$ and the $2 \times 2$ covariance matrix of $A_{q}$ and $\mathrm{C}$ be positive definite. This means that the eigenvalues of the covariance matrices are constrained to be larger than zero. This PD constraint is simple to implement in OpenMx using an mxAlgebra statement, as OpenMx includes a function to calculate eigenvalues (see the OpenMx script). Only constraining $\sigma^{2}$ to be greater than zero is insufficient, as this by itself does not ensure that the covariance matrix of $A_{p}\left(\right.$ or $A_{q}$ ) and $C$ is positive definite. In addition, if $\sigma_{C}^{2}$ were to hit the lower bound, the parameter $\sigma_{\mathrm{AC}}$ would no longer be defined. We repeated simulation 2 with these PD constraints to gauge the effects on the parameters. The results, as obtained with estimated PRS weights, are included in Tables 3 and 4 . These results are largely consistent with those obtained without the PD constraints. We do note that 
the PD constraints affect the distribution of the estimates of $\sigma^{2}{ }_{C}$ positively skewed, as shown in Fig. 4 . Without the positive definiteness constraints, this distribution is normal. In contrast, the distribution of the estimates of $\sigma_{\mathrm{AC}}$ appear to be quite normal, which suggests that, at least in the present

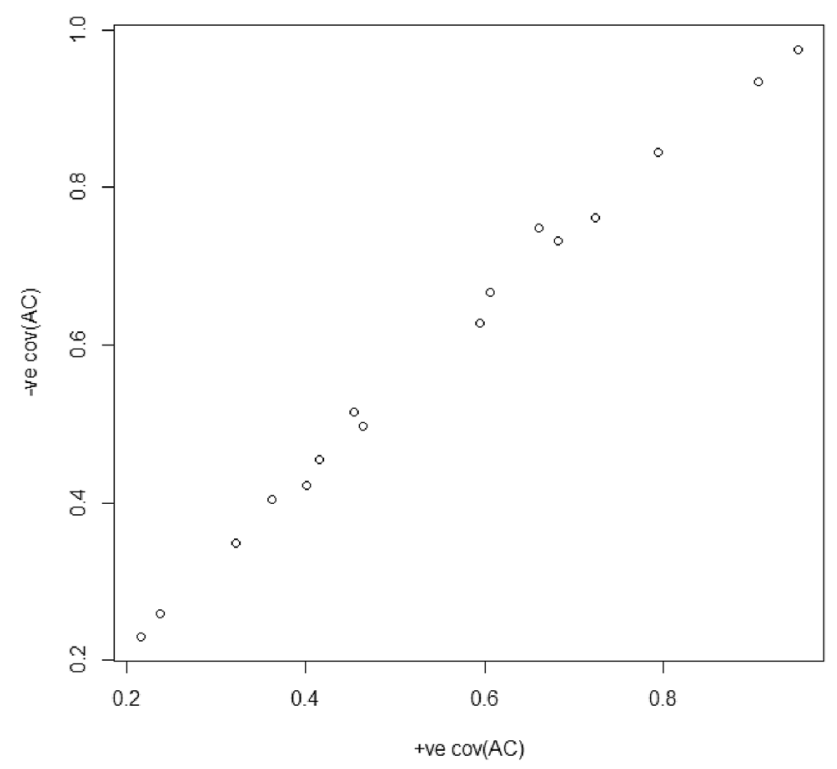

Fig. 3 Power of the LLR test to reject $\sigma_{\mathrm{AC}}=0$ given positive and negative $\sigma_{\mathrm{AC}}$. The parameter settings are given in Table 1 . The only difference is the sign of $\sigma_{\mathrm{AC}}$. The power to reject $\sigma_{\mathrm{AC}}=0$ given positive $\sigma_{\mathrm{AC}}$ is given in Table 1

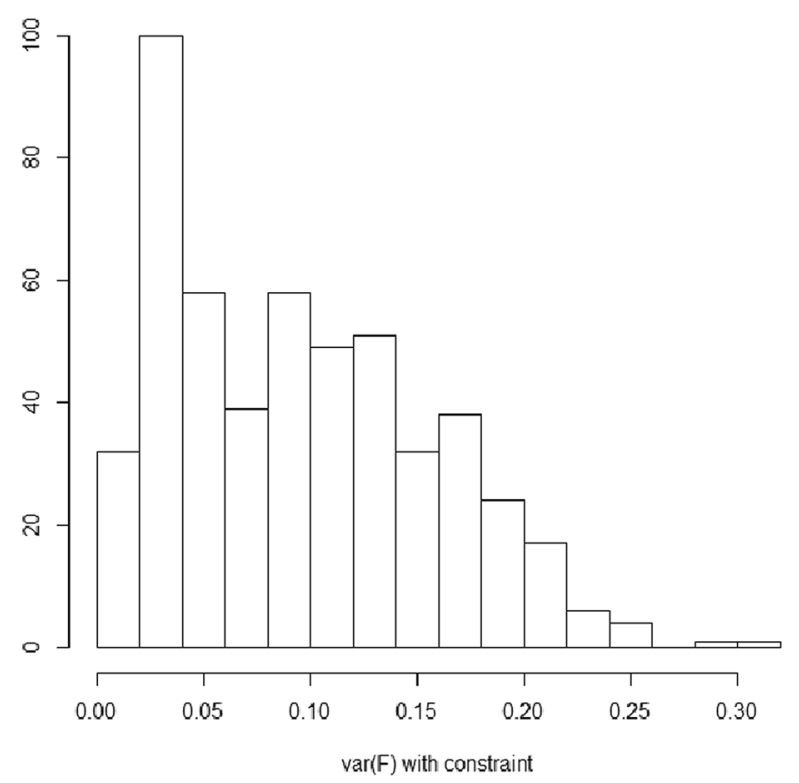

scenario, the LLR test of $\sigma_{\mathrm{AC}}=0$ will not be affected by the PD constraints.

\section{The Identifying Constraint $\sigma_{\mathrm{ApAq}}=0$}

As mentioned above, we have constrained $\sigma_{\mathrm{ApAq}}$ to equal 0 , because it is not possible to estimate the scaling parameter $\mathrm{p}$ (in $\sigma_{\mathrm{PRS}}^{2}=\mathrm{p}^{2} \sigma_{\mathrm{Ap}}^{2}$ ) and the covariance simultaneously. This raises the question how the results are affected if in fact $\sigma_{\mathrm{ApAq}}>0$, as $\sigma_{\mathrm{ApAq}}=0$ is implausible given linkage disequilibrium. In fact, the constraint $\sigma_{\mathrm{ApAq}}=0$ has no effect of the estimates of $\sigma_{\mathrm{AC}}, \sigma_{\mathrm{A}}^{2}$, and $\sigma_{\mathrm{C}}^{2}$. To demonstrate this, we used simulation exact data with $\sigma_{\mathrm{ApAq}}>0$, and fitted the model twice. Once with $\sigma_{\mathrm{ApAq}}$ fixed to its true value, and once $\sigma_{\mathrm{ApAq}}$ fixed to zero. Specifically, we chose the parameter values shown in Table 5. Fitting the model with $\sigma_{\mathrm{ApAq}}$ fixed to equal its true value $\left(\sigma_{\mathrm{ApAq}}=0.1224\right.$; correlation: $\left.\rho_{\mathrm{ApAq}}=0.5\right)$, we recovered the parameter values, including $\sigma_{\mathrm{AC}}=0.077$, and the total additive genetic variance $0.2+0.3+2 * 0.1224=\sim 0.745$ (i.e., $\sigma_{\mathrm{Ap}}^{2}+\sigma_{\mathrm{Aq}}^{2}+2 \sigma_{\mathrm{ApAq}}$ ). The power to reject $\sigma_{\mathrm{AC}}=0$ equals $0.742(\alpha=0.05)$. Fixing $\sigma_{\mathrm{ApAq}}=0$, we obtain identical results, except for the values of $\sigma^{2}$ Ap and $\sigma_{\text {Aq }}^{2}$. The total genetic variance is now composed as follows $0.5199+0.2250=0.745$ (i.e., $\sigma_{\mathrm{Ap}}^{2}+\sigma_{\mathrm{Aq}}^{2}$ ). We checked this result with a wide variety of parameter values. So in principle, one can constrain $\sigma_{\mathrm{ApAq}}$ to equal any sensible value. However, while the estimates and tests of $\sigma_{\mathrm{AC}}, \sigma_{\mathrm{A}}^{2}$,

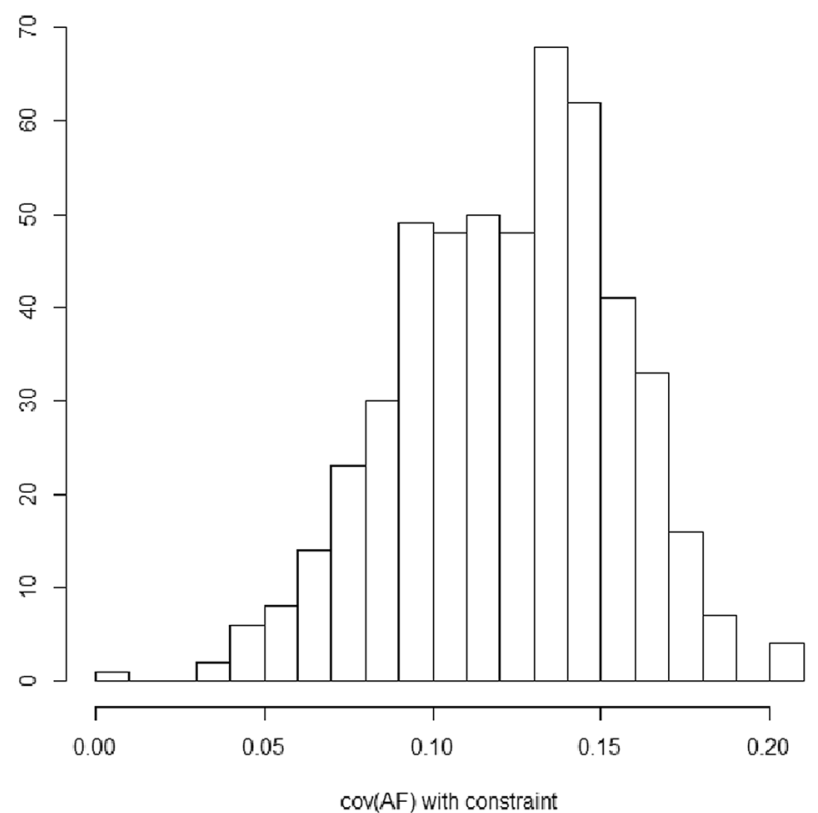

Fig. 4 Distribution of estimates of $\sigma_{\mathrm{F}}^{2}$ (left) and $\sigma_{\mathrm{AF}}$ (right) given positive definiteness constraints (simulation 2 ). The true values are $\sigma_{\mathrm{F}}^{2}=0.091$ and $\sigma_{\mathrm{AF}}=0.125$ 
Table 5 Results with $\sigma_{\mathrm{ApAq}}$ fixed to its true value (row A), and $\sigma_{\mathrm{ApAq}}$ fixed to equal zero (row $\mathrm{B}$ )

\begin{tabular}{llllllllll}
\hline & $\sigma_{\mathrm{Ap}}^{2}$ & $\sigma_{\mathrm{Aq}}^{2}$ & $\sigma_{\mathrm{ApAq}}$ & $\sigma_{\mathrm{A}}^{2}$ & $\sigma_{\mathrm{C}}^{2}$ & $\sigma_{\mathrm{E}}^{2}$ & $\sigma_{\mathrm{AC}}$ & LLR & Power \\
\hline $\mathrm{A}$ & 0.20 & 0.30 & $0.1224^{*}$ & $0.745^{\mathrm{a}}$ & 0.2 & 0.3 & 0.077 & 6.81 & 0.742 \\
$\mathrm{~B}$ & 0.5199 & 0.2250 & $0^{*}$ & $0.745^{\mathrm{b}}$ & 0.2 & 0.3 & 0.077 & 6.81 & 0.742 \\
\hline
\end{tabular}

$\sigma_{\mathrm{ApAq}}=0.122$ corresponds to a correlation of $0.1224 / \mathrm{sqrt}(0.20 * 0.30)=0.5$

$\sigma_{\mathrm{AC}}=0.077$ corresponds to a correlation of $0.077 / \operatorname{sqrt}(0.745 * 0.2)=0.2$

Power: to reject $\sigma_{\mathrm{AC}}=0$ is given $\alpha=0.05$, and $\mathrm{Nmz}=1000, \mathrm{Ndz}=1000$, based on the LLR statistic

*Fixed parameters

${ }^{\mathrm{a}} \sigma_{\mathrm{A}}^{2}=0.745=0.30+0.30+2 * 0.1224$

${ }^{\mathrm{b}} \sigma_{\mathrm{A}}^{2}=0.745=0.5199+0.2250$

and $\sigma_{C}^{2}$ are unaffected, we note that the values of $\sigma_{\text {Ap }}^{2}$ and $\sigma_{\text {Aq }}^{2}$ do depend on this sensible value.

\section{Discussion}

The present aim was to estimate A-C covariance in the classical twin model with PRS. To this end, we proposed the model depicted in Fig. 1, in which the covariance between $A_{p}$ (PRS) and $A_{q}$ and $C$ are modeled as a function of the single covariance of $A\left(A_{p}+A_{q}\right)$ and $C$. We found that the power to reject $\sigma_{\mathrm{AC}}=0$ depends mainly on the proportion of phenotypic variance due to the covariance term $\left(\sigma_{\mathrm{AC}}\right)$ and the PRS, where the former is more important than the latter. We investigated the influence of using estimated PRS weights. The use of estimated weights resulted in downwards bias of $\sigma_{\mathrm{Ap}}$ and an upwards bias of $\sigma_{\mathrm{Aq}}$. However, the estimate of $\sigma_{\mathrm{AC}}$ was not affected. The use of estimated weights had a small effect of the Type I error rate in the test of $\sigma_{\mathrm{AC}}=0$.

In the most favorable settings qua power $(8,14$, and 16 in Table 1), the proportions $p r 2 \sigma_{\mathrm{AC}}$ (phenotypic variance due to $\sigma_{\mathrm{AC}}$ ) equaled $0.153,0.159$, and 0.189 , and the proportions $p r \mathrm{Ph}$ (phenotype variance due to the PRS) equaled $0.101,0.168$ and 0.162 . We consider these values $(p r P h)$ to be generally large by today's standards, but note that, while $p r 2 \sigma_{\mathrm{AC}}$ is given, the proportion $p r \mathrm{Ph}$ is likely to increase with the ongoing progress of GWAS meta analyses of many phenotypes. For instance, at present PRSs explain 15\% of the variance of educational attainment and $\sim 11 \%$ of the variance of IQ (Allegrini et al. 2019).

The results of the power study and simulations shed some light on the viability of the model. But the results of simulation 2 also demonstrated that positive cultural transmission can result in large $\mathrm{C}$ in the standard ACE model, while most of this $\mathrm{C}$ variance is due to $\sigma_{\mathrm{AC}}$. The actual $\mathrm{C}$ variance (without $\sigma_{\mathrm{AC}}$ ) can be quite small. It is therefore advisable to fit the model with the positive definiteness constraint, outlined above. In this connection, we note that the finding that $\mathrm{C}$ variance in cognitive abilities is large in young children, but declines quickly in magnitude as children grow older
(Haworth et al. 2010; Tucker-Drob and Bates 2016) may well be due to a decline in the magnitude of cultural transmission, in combination with an increase in genetic variance. This may be testing by extending the present model to include age as a moderator in the manner of Purcell (2002). This is relatively simple to do in OpenMx. In this connection, we also note that the estimate of $\sigma_{\mathrm{AC}}$ obtained using the present model may tell us that $\sigma_{\mathrm{AC}}$ is present. It does not, unlike other models, reveal the source of the $\sigma_{\mathrm{AC}}$. For instance, in the NTF design, cultural transmission is the source the covariance between A and F, where the distinction is made between $\mathrm{F}$ (shared environmental effects due to cultural transmission) and residual $\mathrm{C}$, which we denoted $\mathrm{C}^{*}$ above.

We considered negative $\sigma_{\mathrm{AC}}$ in the power study, and found that the power to reject $\sigma_{\mathrm{AC}}=0$ was about the same regardless of the sign of $\sigma_{\mathrm{AC}}$. We note that negative $\sigma_{\mathrm{AC}}$ (e.g., originating in negative cultural transmission) tends to produce twin correlations, which are suggestive of an ADE model $\left(2 * r_{D Z}<r_{M Z}\right)$. This is to be expected as $-\sigma_{A C}$ lowers the MZ and DZ correlations to the same extent. Finally, the present results demonstrated that the addition of PRSs to the ACE model increases the power to detect $C$ variance, assuming $\sigma_{\mathrm{AC}}=0$. This may be of interest, as in the classical twin model, the power to detect $\mathrm{C}$ variance is known to be generally poor (Visscher et al. 2008; Martin et al. 1978).

In closing, we note the following limitations. We have assumed that dominance variance (D) is absent, and acknowledge that the twin univariate design is limited to ACE or ADE. As demonstrated by Keller et al. (2010), a well fitting ACE model does not rule out the represent of D. It is possible that the addition of PRSs may aid in resolving D (in an ACDE) model, but we consider this beyond the present scope. Boomsma et al (2020; see this issue) showed that it is possible to estimate all four variance components (A, C, D, and E) in special cases of the multivariate twin model. Second as mentioned above, the settings of the power study and the simulations are limited in scope. In addition, we considered only equal $\mathrm{MZ}$ and $\mathrm{DZ}$ sample sizes $(\mathrm{Nmz}=\mathrm{Ndz}=1000)$. The ratio $\mathrm{Nmz} / \mathrm{Ndz}$ has a general bearing on the power in the twin design (Visscher 2004). 
However, power calculations with unequal MZ and DZ sample sizes are simple to carry out. Third, the simulations that we carried out to gauge the effect of using estimated PRS weights, involved only a small number of associated GVs with relatively large effects. Simulation studies with more realistic designs will provide additional information concerning the effects of using estimated PRS weights. Fourth, we assumed that phenotypic mating is random. However, we note that the PRSs in the DZ twins offer the means to tests this, as the correlation between the additive genetic PRSs will equal 0.5 given phenotypic random mating. In addition, the present model may be extended to include parental data to accommodate phenotypic assortative mating as outlined in Keller et al. (2009). Fifth, we have not considered the effect of violations of other standard twin design assumptions on the estimate of $\sigma_{\mathrm{AC}}$ (Eaves et al. 1977; Purcell 2002; Keller et al 2010). Genotype-unshared environment covariance $\left(\sigma_{\mathrm{AE}}\right)$ is not identified in the present model. Unmodeled (positive) $\sigma_{\mathrm{AE}}$ and $\mathrm{A} \times \mathrm{C}$ interaction contribute to $\mathrm{A}$. We do not see how either could result in spurious $\sigma_{\mathrm{AC}} . \mathrm{A} \times \mathrm{E}$ and $\mathrm{C} \times \mathrm{E}$ interaction contribute to $\mathrm{E}$, which has no bearing on $\mathrm{A}, \mathrm{C}$, or $\sigma_{\mathrm{AC}}$. Sixth, we have not considered the possibility that the $\sigma_{\mathrm{AC}}$ is due to stratification. We know that spatial (geographical) allele frequency gradients may given rise to spurious $\mathrm{C}$ variance in the classical twin design (Tamimy et al. 2020; see this issue). A positive spatial correlation between $\mathrm{C}$ effects and allele frequencies, may given rise to $\mathrm{A}-\mathrm{C}$ covariance. One way to detect this by including as fixed covariates principal components that reflect the allele frequency gradient (Price et al. 2006). If this kind of stratification is an issue, then the size of the $\mathrm{C}$ variance (see Tamimy et al. 2020) and the size of the A-C covariance should decline following the introduction of these covariates. Finally, we have assumed that the PRSs weights were obtained from GWASs of the phenotype of interest. Whether the present approach can be adapted to handle PRSs weights based on a genetically correlated phenotype (i.e., correlated with the phenotype of interest) remains to be seen.

Supplementary Information The online version of this article (https:// doi.org/10.1007/s10519-020-10035-7) contains supplementary material, which is available to authorized users.

Acknowledgements CVD acknowledges NWO top-talent grant 40612-124 (awarded to the late Janneke de Kort); DIB acknowledges KNAW Academy Professor Award (PAH/6635); MCN, CVD, DIB and CCM were supported by National Institute on Drug Abuse grants (DA049867 \& DA018673; PI: MCN). CCM acknowledges grant 5R37 MH107649. We thank the editor David Evans, and the reviewers Matt Keller, Yongkang Kim, and Brad Verhulst for their helpful comments.

\section{Compliance with ethical standards}

Conflict of interest Conor V. Dolan, Roel C. A. Huijskens, Camelia C. Minică , Michael C. Neale, \& Dorret I. Boomsma declare that they have no conflicts of interest related to the publication of this article.

Ethical approval This article does not contain any studies with human participants or animal subjects performed by any of the authors.

Open Access This article is licensed under a Creative Commons Attribution 4.0 International License, which permits use, sharing, adaptation, distribution and reproduction in any medium or format, as long as you give appropriate credit to the original author(s) and the source, provide a link to the Creative Commons licence, and indicate if changes were made. The images or other third party material in this article are included in the article's Creative Commons licence, unless indicated otherwise in a credit line to the material. If material is not included in the article's Creative Commons licence and your intended use is not permitted by statutory regulation or exceeds the permitted use, you will need to obtain permission directly from the copyright holder. To view a copy of this licence, visit http://creativecommons.org/licenses/by/4.0/.

\section{References}

Allegrini AG, Selzam S, Rimfeld K, von Stumm S, Pingault JB, Plomin R (2019) Genomic prediction of cognitive traits in childhood and adolescence. Mol Psychiatry 24(6):819-827. https:// doi.org/10.1038/s41380-019-0394-4

Bates TC, Maher BS, Medland SE et al (2018) The nature of nurture: using a virtual-parent design to test parenting effects on children's educational attainment in genotyped families. Twin Res Hum Genet 21(2):73-83. https://doi.org/10.1017/thg.2018.11

Beam CR, Turkheimer E (2013) Phenotype-environment correlations in longitudinal twin models. Dev Psychopathol 25:7-16

Bekker PA, Merckens A, Wansbeek TJ (1994) Identification, equivalent models, and computer algebra: statistical modeling and decision science. Academic Press, New York

Boker SM, Neale MC, Hermine H, Maes HH, Wilde MJ, Spiegel M, Brick TR, Spies J, Estabrook R, Kenny S, Bates TC, Mehta P, Fox J (2011) OpenMx: an open source extended structural equation modeling framework. Psychometrika. https://doi. org/10.1007/s11336-010-9200-6

Boomsma DI, van Beijsterveldt CEM, Odintsova VV, Neale MC, Dolan CV (2020) Genetically informed regression analysis: application to aggression prediction by inattention and hyperactivity in children and adults. Behav Genet. https://doi. org/10.1007/s10519-020-10025-9. (Online ahead of print).

Carey G (1986) Sibling imitation and contrast effects. Behav Genet 16:319-341. https://doi.org/10.1007/BF01071314

Cheesman R, Hunjan A, Coleman JRI et al (2020) Comparison of adopted and nonadopted individuals reveals gene-environment interplay for education in the UK Biobank. Psychol Sci 31(5):582-591. https://doi.org/10.1177/0956797620904450

D’Onofrio BM, Turkheimer EN, Eaves LJ, Corey LA, Berg K, Solaas $\mathrm{MH}$ et al (2003) The role of the children of twins design in elucidating causal relations between parent characteristics and child outcomes. J Child Psychol Psychiatry 44(8):1130-1144

Dolan CV, de Kort JM, van Beijsterveldt TC, Bartels M, Boomsma DI (2014) GE covariance through phenotype to environment transmission: an assessment in longitudinal twin data and application to childhood anxiety. Behav Genet 44(3):240-253. https ://doi.org/10.1007/s10519-014-9659-5

Dudbridge F (2013) Power and predictive accuracy of polygenic risk scores. PLoS Genet 9(3):e1003348. https://doi.org/10.1371/ 
journal.pgen.1003348. Epub 2013 Mar 21. Erratum in: PLoS Genet 2013 Apr;9(4)

Eaves LE, Erkanli A (2003) Markov Chain Monte Carlo Approaches to Analysis of Genetic and Environmental Components of Human Developmental Change and $\mathrm{G} \times \mathrm{E}$ Interaction. Behav Genet 33:279-299. https://doi.org/10.1023/A:1023446524917

Eaves LJ, Last K, Martin NG, Jinks JL (1977) A progressive approach to non-additivity and genotype-environmental covariance in the analysis of human differences. Br J Math Stat Psychol 30(1):1-42

Eaves LJ, Last KA, Young PA, Martin NG (1978) Model-fitting approaches to the analysis of human behavior. Heredity 41:249-320

Evans DM, Visscher PM, Wray NR (2009) Harnessing the information contained within genome-wide association studies to improve individual prediction of complex disease risk. Hum Mol Genet 18:3525-3531

Fulker DW (1988) Genetic and cultural transmission in human behavior. In: Weir BS, Eisen EJ, Goodman MM, Namkoong G (eds) Proceedings of the second international conference on quantitative genetics. Sinauer, Sunderland, MA, pp 318-340

Fulker DW, Cherny SS, Sham PC, Hewitt JKR (1999) Combined linkage and association sib-pair analysis for quantitative traits. Am J Hum Genet 64(1):259-267. https://doi.org/10.1086/302193

Haworth CM, Wright MJ, Luciano M, Martin NG, de Geus EJ, van Beijsterveldt CE, Bartels M, Posthuma D, Boomsma DI, Davis OS, Kovas Y, Corley RP, Defries JC, Hewitt JK, Olson RK, Rhea SA, Wadsworth SJ, Iacono WG, McGue M, Thompson LA, Hart SA, Petrill SA, Lubinski D, Plomin R (2010) The heritability of general cognitive ability increases linearly from childhood to young adulthood. Mol Psychiatry 15(11):1112-1120. https://doi. org/10.1038/mp.2009.55

Heath AC, Kendler KS, Eaves LJ, Markell D (1985) The resolution of cultural and biological inheritance: informativeness of different relationships. Behav Genet 15(5):439-465

Jinks JL, Fulker DW (1970) Comparison of the biometrical genetical, MAVA, and classical approaches to the analysis of the human behavior. Psychol Bull 73(5):311-349. https://doi.org/10.1037/ h0029135

Keller MC, Medland SE, Duncan LE (2010) Are extended twin family designs worth the trouble? A comparison of the bias, precision, and accuracy of parameters estimated in four twin family models. Behav Genet 40(3):377-393. https://doi.org/10.1007/s1051 9-009-9320-x

Keller MC, Medland SE, Duncan LE, Hatemi PK, Neale MC, Maes HHM, Eaves LJ (2009) Modeling extended twin family data I: description of the cascade model. Twin Res Hum Genet 12(1):8-18

Kendler KS (2011) A conceptual overview of gene-environment interaction and correlation in a developmental context. In: Kendler KS, Jaffee SR, Romer D (eds) The dynamic genome and mental health: the role of genes and environments in youth development. Oxford University Press, New York, pp 5-28

Knafo A, Jaffee SR (2013) Gene-environment correlation in developmental psychopathology. Dev Psychopathol 25:1-6. https://doi. org/10.1017/S0954579412000855

Kong A, Thorleifsson G, Frigge ML, Vilhjalmsson BJ, Young AI, Thorgeirsson TE, Benonisdottir S, Oddsson A, Halldorsson BV, Masson G, Gudbjartsson DF (2018) The nature of nurture: effects of parental genotypes. Science 359:424-428. https://doi. org/10.1126/science.aan6877

Maes HH, Neale MC, Kendler KS, Martin NG, Heath AC, Eaves LJ (2006) Genetic and cultural transmission of smoking initiation: an extended twin kinship model. Behav Genet 36(6):795-808
Martin NG, Eaves LJ, Kersey MJ, Davies P (1978) The power of the classical twin study. Heredity 40:97-116. https://doi.org/10.1038/ hdy. 1978.10

Minică CC, Dolan CV, Boomsma DI, de Geus E, Neale MC (2018) Extending causality tests with genetic instruments: an integration of Mendelian randomization with the classical twin design. Behav Genet 48:337-349

Narusyte J, Neiderhiser JM, D’Onofrio BM, Reiss D, Spotts EL, Ganiban J, Lichtenstein P (2008) Testing different types of genotypeenvironment correlation: an extended children-of-twins model. Dev Psychol 44(6):1591-1603. https://doi.org/10.1037/a0013911

Neale MC (2000) Flexible QTL mapping with Mx. In: Spector T, Snieder H, MacGregor A (eds) Advances in twin and sib pair analysis. Greenwich Medical Media, London, pp 219-243

Neale MC, Fulker DW (1984) A bivariate path analysis of fear data on twins and their parents. Acta Genet Med Gemellol 33:273-286

Neale MC, de Knijff P, Havekes LM, Boomsma DI (2000) ApoE polymorphism accounts for only part of the genetic variation in quantitative ApoE levels. Genet Epidemiol 18:331-340

Neale MC, Hunter MD, Pritikin JN, Zahery M, Brick TR, Kirkpatrick RM, Estabrook R, Bates TC, Maes HH, Boker SM (2016) OpenMx 2.0: extended structural equation and statistical modeling. Psychometrika 81(2):535-49

Plomin R, DeFries JC, Loehlin JC (1977) Genotype-environment interaction and correlation in the analysis of human behavior. Psychol Bull 84:309-322. https://doi.org/10.1037/0033-2909.84.2.309

Plomin R, Loehlin JC, DeFries JC (1985) Genetic and environmental components of "environmental" influences. Dev Psychol 21(3):391-402

Plomin R, DeFries JC, Knopik VS, Neiderhise JM (2016) Top 10 replicated findings from behavioral genetics. Perspect Psychol Sci 11(1):3-23. https://doi.org/10.1177/1745691615617439

Polderman TJC, Benyamin B, de Leeuw CA, Sullivan PF, van Bochoven A, Visscher PM, Posthuma D (2015) Meta-analysis of the heritability of human traits based on fifty years of twin studies. Nat Genet 47:702-709

Price A, Patterson N, Plenge R et al (2006) Principal components analysis corrects for stratification in genome-wide association studies. Nat Genet 38:904-909. https://doi.org/10.1038/ng1847

Purcell S (2002) Variance components models for gene-environment interaction in twin analysis. Twin Res 5:554-571

Purcell SM, Wray NR, Stone JL, Visscher PM, O'Donovan MC, Sullivan $\mathrm{PF}$ et al (2009) Common polygenic variation contributes to risk of schizophrenia and bipolar disorder. Nature 460(7256):748 752. https://doi.org/10.1038/nature08185

R Core Team (2018) R: a language and environment for statistical computing. R Foundation for Statistical Computing, Vienna, Austria. URL https://www.R-project.org/

Rutter M, Silberg J (2002) Gene-environment interplay in relation to emotional and behavioral disturbance. Annu Rev Psychol 53:463-490

Scarr S, McCartney K (1983) How people make their own environments: a theory of genotype $\rightarrow$ environment effects. Child Dev 54:424-435

Selzam S, Ritchie SJ, Pingault J-B, Reynolds CA, O'Reilly PF, Plomin R (2019) Comparing within- and between-family polygenic score prediction. Am J Hum Genet 105:351-363. https://doi. org/10.1016/j.ajhg.2019.06.006

Tamimy Z, Kevenaar ST, Hottenga JJ, Hunter MD, de Zeeuw EL, Neale MC, van Beijsterveldt CEM, Dolan CV, van Bergen E, Boomsma DI (2020) Multilevel twin models: geographical region as a third level variable. Behav Genet. bioRxiv. https:// doi.org/10.1101/2020.11.11.377820.

Tucker-Drob EM, Bates TC (2016) Large cross-national differences in gene $\times$ socioeconomic status interaction on intelligence. Psychol Sci 27(2):138-149 
van Beijsterveldt CEM, Middeldorp CM, Slof-Op't Landt MCT, Bartels M, Hottenga JJ, Eka H, Suchiman D, Slagboom PE, Boomsma DI (2011) Influence of candidate genes on attention problems in children: a longitudinal study. Behav Genet 41:155-164. https:// doi.org/10.1007/s10519-010-9406-5

van den Oord EJCG, Snieder H (2002) Including measured genotypes in statistical models to study the interplay of multiple factors affecting complex traits. Behav Genet 32(1):1-22

van der Molenaar D, Sluis S, Boomsma DI, Dolan CV (2012) Detecting specific genotype by environment interactions using marginal maximum likelihood estimation in the classical twin design. Behav Genet 42:483-499. https://doi.org/10.1007/s1051 9-011-9522-x

van der Sluis S, Dolan CV, Neale MC, Posthuma D (2008) Power calculations using exact data simulation: a useful tool for genetic study designs. Behav Genet 38:202-211

van Dongen J, Slagboom P, Draisma H et al (2012) The continuing value of twin studies in the omics era. Nat Rev Genet 13:640-653. https://doi.org/10.1038/nrg3243

Verhulst B, Hatemi PK (2013) Gene-environment interplay in twin models. Polit Anal 21(3):368-389. https://doi.org/10.1093/pan/ mpt005

Verhulst B, Prom-Wormley E, Keller M, Medland S, Neale MC (2019) Type I error rates and parameter bias in multivariate behavioral genetic models. Behav Genet 49:99-111. https://doi.org/10.1007/ s10519-018-9942-y

Visscher P (2004) Power of the classical twin design revisited. Twin Res 7(5):505-512. https://doi.org/10.1375/twin.7.5.505

Visscher M, Gordon S, Neale MC (2008) Power of the classical twin design revisited: II detection of common environmental variance. Twin Res Hum Genet 11(1):48-54. https://doi.org/10.1375/ twin.11.1.48

Warrington NM, Freathy RM, Neale MC, Evans DM (2018) Using structural equation modelling to jointly estimate maternal and fetal effects on birthweight in the UK Biobank. Int J Epidemiol 47(4):1229-1241. https://doi.org/10.1093/ije/dyy015

Wertz J, Moffitt TE, Agnew-Blais J, Arseneault L, Belsky DW, Corcoran DL, Houts R, Matthews T, Prinz JA, Richmond-Rakerd LS, Sugden K, Caspi A (2018) Using DNA from mothers and children to study parental investment in children's educational attainment. Child Dev. https://doi.org/10.1111/cdev.13329

Publisher's Note Springer Nature remains neutral with regard to jurisdictional claims in published maps and institutional affiliations. 